\title{
A construção de um projeto coletivo na perspectiva da pedagogia histórico-crítica
}

\section{Roberta Negrão de Araújo Aparecido de Sampaio Baptista Universidade Estadual do Norte do Paraná}

Mara Peixoto Pessôa

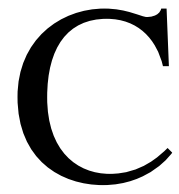

onsiderando o Programa de Expansão e Melhoria do Ensino Médio (PROEM) proposto, na década de 1990, pela Secretaria de Estado da Educação (SEED) do Paraná com o intuito de efetivar o desmantelamento dos cursos profissionalizantes - a direção e a equipe pedagógico-administrativa do Colégio Estadual "Cristo Rei”, de Ensino Médio, modalidade Normal, resolveram reunir-se sistematicamente para discutirem os rumos que a instituição tomaria a partir da política estadual. Dessa forma, o referido colégio, situado em Cornélio Procópio/Paraná, organizou um grupo de estudos que se reunia bimestralmente. Mesmo com a rotatividade de professores, a escola manteve-se firme em seu propósito de não aceitar o fim da oferta do curso de formação de professores - anteriormente denominado magistério - e, assim, tornaram-se hábito os encontros para discussões, ora para estudos da legislação, ora para análise do Projeto Político Pedagógico, e das demais questões do entorno de uma escola pública.

Em 2003, com a mudança de governo, tanto no âmbito nacional como estadual, houve a reorganização do curso de Formação de Docentes, uma proposição do recém-criado Departamento de Educação Profissional (DEP) na SEED. Neste contexto, a comunidade escolar foi percebendo a necessidade de discutir os fundamentos propostos pela perspectiva teórica assumida. Destarte, conforme solicitação dos professores e da equipe pedagógica, surgiu o Projeto "Lendo e Aprendendo: construindo uma escola crítica", que teve início no referido ano. Obtendo êxito, permaneceu, tornado-se institucional.

Em 2007, pela parceria estabelecida com a Universidade Estadual do Norte do Paraná (UENP), campus Cornélio Procópio, tornou-se um Projeto de Extensão da referida Instituição de Ensino Superior (IES), proposto pela Pro-

Filosofia e Educação - ISSN 1984-9605 - v. 4, no 1, abril-setembro de 2012 
fessora Mara Peixoto Pessôa. A princípio o projeto versou sobre as normas de Associação Brasileira de Normas Técnicas (ABNT), a elaboração de Projeto de Pesquisa, seus elementos constitutivos e sua concepção filosófica.

Em 2008 houve, por parte dos envolvidos, a solicitação de continuidade. Assim, tendo em vista a dificuldade teórica no que diz respeito aos fundamentos da educação, foi selecionada a obra História das Ideias Pedagógicas no Brasil (2007), do educador Dermeval Saviani. Nesta etapa, os professores do Centro Estadual de Educação Básica de Jovens e Adultos (CEEBJA) também participaram dos estudos. A leitura da obra foi feita por todos os envolvidos; e a divisão, para apresentação dos períodos propostos, em forma de seminário, aconteceu independente da área de formação, privilegiando a diversidade. Além da leitura e das apresentações dos seminários, nesta fase, em encontros mensais, os inscritos participaram do I Seminário de Pesquisa, Ensino e Extensão proposto pela IES, tanto como ouvintes quanto com a apresentação de pôster e comunicação oral.

A avaliação do projeto, além de relato individual, deu-se pela elaboração de um artigo científico, tendo como foco o período apresentado. Ao término, foi registrado pelos cursistas a relevante contribuição do projeto no que tange à compreensão da proposta assumida pela SEED/PR, bem como de seu subsídio teórico e, ainda a melhoria da práxis pedagógica.

\section{História das ideias pedagógicas no Brasil: nova proposta de periodização}

A obra é resultado de um processo de pesquisa que teve início em 1996. Tem como objetivo compor uma visão de conjunto da história da educação brasileira, auxiliando os professores no trabalho pedagógico que realizam com seus alunos nas salas de aula.

Na introdução é apresentado o problema objeto de investigação: a compreensão da evolução do pensamento pedagógico brasileiro a partir da identificação, classificação e periodização das principais concepções tradicionais (até então inédito). Referem-se às obras de Gadotti, Pensamento Pedagógico Brasileiro (1987) e História das Ideias Pedagógicas (1993). No entanto, comenta a

Filosofia e Educação - ISSN 1984-9605 - v. 4, no 1, abril-setembro de 2012 
ausência da perspectiva histórica na primeira e aponta que a segunda traz o inventário de dez autores brasileiros, todos eles situados no século XX.

Aborda a perspectiva teórico-metodológica que orientou a pesquisa:

- Primeiro princípio: a superação dos limites dos paradigmas tradicionais da historiografia representados pelo positivismo e presentismo, em interlocução ativa e crítica com as correntes atuais que resultaram das contribuições da "Escola dos Annales" e que se difundiram sob a denominação de "História Nova". Considera-se que o conhecimento em geral e, especificamente, o conhecimento histórico-educacional configura um movimento que parte do todo caótico (síncrese) e atinge, por meio da abstração (análise), o todo concreto (síntese).

- Segundo princípio metodológico da referência teórica proposta: adoção da perspectiva de longa duração (um princípio tanto da "Escola dos Annales" como da orientação metodológica proposta por Gramsci: para se captar os movimentos orgânicos (estruturais) é necessário submeter à análise períodos relativamente longos).

- Terceiro princípio: o olhar analítico-sintético no trato com as fontes (levantamento e exame atento das informações disponíveis).

- Quarto princípio: articulação do singular e do plural, garantindo o empenho em encontrar a justa relação entre o local, o nacional e o internacional (detectar em que grau o local ou nacional constituem expressões de tendências que se impõem internacionalmente/ relações de reciprocidade, determinação e subordinação).

- Quinta diretriz teórico-metodológica: princípio da atualidade da pesquisa histórica, que implica a consciência de que toda investigação histórica não é desinteressada $=$ percepção de que o presente se enraíza no passado e se projeta no futuro.

Destaca, também, os materiais básicos: documentos escritos nos quais se encontram as ideias pedagógicas (livros, artigos e textos oficiais - exposições de motivos, justificativas de leis, decretos e demais disposições normativas). Assim, o método é de caráter historiográfico, com técnicas de manipulação, análise e interpretação de documentos, cujo conteúdo foi confrontado com os

Filosofia e Educação - ISSN 1984-9605 - v. 4, no 1, abril-setembro de 2012 
determinantes histórico-sociais visando a evidenciar, pela reflexão crítica, o significado das ideias pedagógicas na sequência das transformações históricas. A hipótese de trabalho é a classificação e periodização das ideias pedagógicas. Assim, discute que:

- A história das ideias é o "território historiográfico" mais abalado. 1970: história das mentalidades/ 1980: história cultural.

- Ideias educacionais X ideias pedagógicas: referem-se à educação (concepção de homem, mundo e sociedade, sob cuja luz se interpreta o fenômeno educativo) X ideias da substância da prática educativa (o adjetivo "pedagógico" tem ressonância metodológica, denotando o modo de realizar o ato educativo).

- O estudo mostra que a necessidade, de certa forma consensual, de se superar a visão tradicional não implica necessariamente a renúncia à compreensão articulada e racional do movimento objetivo em favor de uma abordagem relativista e fragmentada.

- Periodização (Braudel): eventos (o tempo curto dos acontecimentos); períodos (o tempo médio das conjunturas) e processo global (o tempo longo das estruturas) $=$ terminologia presa aos limites formalistas próprios de uma lógica determinista que caracteriza o estruturalismo. "regularidades e permanência dos sistemas".

- Abordagem de Gramsci: sugere uma metodologia que permite dar conta mais satisfatoriamente da história como um processo cujo movimento necessita ser reconstruído pelo historiador.

A periodização, enquanto uma exigência de compreensão do objeto, é, antes, uma questão teórica que se põe para o historiador ao enfrentar a tarefa de organizar os dados visando a explicar o fenômeno que se propôs investigar. Assim, as perguntas formuladas terão respostas conforme a perspectiva teórica em que se coloca o historiador.

- Na história da educação brasileira, a periodização adotada se guiava pelo parâmetro político (período colonial, no Império e na República). As críticas a essa forma de periodizar levaram ao critério da determinação econômica - Romanelli (1978) e Ribeiro (1998) .Todavia, a tendência em curso é buscar uma pe-

Filosofia e Educação - ISSN 1984-9605 - v. 4, no 1, abril-setembro de 2012 
riodização centrada não nos aspectos externos, mas naqueles internos ao processo educativo.

Considerando a pesquisa realizada, bem como a articulação dos três níveis de análise - os níveis da filosofia da educação, da teoria da educação e da prática pedagógica - Saviani construiu uma periodização preliminar, distribuindo-as em oito períodos, determinando, ainda, os eventos a partir dos quais foram definidos os marcos:

$\checkmark \quad 1^{\circ}$ Período (1549 -1759): monopólio da vertente religiosa da pedagogia tradicional. Evento: 1549 - chegada ao Brasil dos primeiros jesuítas chefiados pelo Pe. Manoel da Nóbrega.

$\checkmark \quad 2^{\circ}$ Período (1759 - 1932): coexistência entre as vertentes religiosa e leiga da pedagogia tradicional. Evento: 1759 - expulsão dos jesuítas pelo Marquês de Pombal.

$\checkmark \quad 3^{\circ}$ Período $(1932-1947)$ : equilíbrio entre a pedagogia tradicional e a pedagogia nova. Evento: 1932 - divulgação do "Manifesto dos Pioneiros da Educação Nova".

$\checkmark \quad 4^{\circ}$ Período (1947 - 1961): predomínio da influência da pedagogia nova. Evento: 1947 - elaboração do anteprojeto da Lei de Diretrizes e Bases da Educação Nacional.

$\checkmark \quad 5^{\circ}$ Período (1961 - 1969): crise da pedagogia nova e articulação da pedagogia tecnicista. Evento: 1961 - promulgação da primeira LDB.

$\checkmark \quad 6^{\circ}$ Período (1969 - 1980): predomínio da pedagogia tecnicista. Evento: 1969 - entra em vigor a Lei no 5540 (reforma universitária).

$\checkmark \quad 7^{\circ}$ Período (1980 - 1991): emergência da pedagogia histórico-crítica e propostas alternativas. Evento: 1980 - realização da I Conferência Brasileira de Educação (CBE): exigência de se formular uma pedagogia crítica.

$\checkmark \quad 8^{\circ}$ Período (1991 - 1996): neoconstrutivismo, neotecnicismo, neo-escolanovismo. Evento: 1991 - realização da sexta e última CBE (ducha de água fria no entusiasmo para formulação e as tentativas de implantação de propostas pedagógicas críticas). Evento: 1996 - realização do I Congresso Nacional de Educação (CONED) e promulgação da segunda LDB (resistência às idéias pedagógicas dominantes).

Filosofia e Educação - ISSN 1984-9605 - v. 4, no 1, abril-setembro de 2012 
Esta periodização deu início á investigação até a conclusão da primeira etapa (1996 - 1998). Diante do problema detectado ao final da primeira etapa da pesquisa, Saviani (2007) procurou, na segunda (1998-2000), apresentar a seguinte periodização:

* Primeiro Período: As ideias pedagógicas no Brasil entre 1549 e 1759: Monopólio da vertente religiosa da pedagogia tradicional.

1. Uma pedagogia brasílica ou o período heroico (1549-1599)

2. A institucionalização da pedagogia jesuítica ou o Ratio Studiorum (15991759).

* Segundo Período: As ideias pedagógicas no Brasil entre 1759 e1932: coexistência entre as vertentes religiosa e leiga da pedagogia tradicional

1. A pedagogia pombalina ou as ideias pedagógicas do despotismo esclarecido (1759-1827)

2. Desenvolvimento da pedagogia leiga: ecletismo, liberalismo e positivismo (1827-1932)

* Terceiro Período: As ideias pedagógicas no Brasil entre 1932 e 1969: predomínio da Pedagogia Nova

1. Equilíbrio entre a pedagogia tradicional e a pedagogia nova (1932-1947)

2. Predomínio da influência da pedagogia nova (1947-1961)

3. Crise da pedagogia nova e articulação da pedagogia tecnicista (1961-1969)

- Quarto Período: As ideias pedagógicas no Brasil entre 1969 e 2001: configuração da concepção pedagógica produtivista.

1. Predomínio da pedagogia tecnicista, manifestações da concepção analítica de filosofia da educação e concomitante desenvolvimento da visão críticoreprodutivista (1969-1980)

2. Ensaios contra-hegemônicos: pedagogias da "educação popular", pedagogias da prática, pedagogia crítico-social dos conteúdos e pedagogia histórico-crítica (1980-1991)

3. O neoprodutivismo e suas variantes: neo-escolanovismo, neoconstrutivismo e neotecnicismo (1991-2001).

O princípio de periodização que guiou a distribuição das ideias pedagógicas nos períodos indicados baseia-se na noção de predominância ou hegemonia

Filosofia e Educação - ISSN 1984-9605 - v. 4, no 1, abril-setembro de 2012 
(cada período corresponde a predominância de determinadas ideias, o que os diferencia entre si). A periodização proposta justifica-se em razão do tipo e dos propósitos da investigação realizada; outras formas de periodização das ideias pedagógicas são possíveis.

Consideramos que a historicidade do fenômeno educativo, assim como o conhecimento deste, fornece em seu desenvolvimento histórico-objetivo, elementos da maior relevância não apenas para entender a educação, mas também para realizá-la.

\section{Pedagogia histórico-crítica: contextualização no Brasil}

Foi em 1991, na obra Pedagogia histórico-crítica: primeiras aproximações, que Saviani cunhou tal denominação, pois a mesma vinha sendo passível de diferentes interpretações, desde sua apresentação como uma pedagogia "revolucionária" na obra Escola e Democracia (1983).

Tal perspectiva, especialmente no Brasil, firmou-se como teoria que busca captar o movimento objetivo do processo histórico, uma vez que concebe o homem por meio do materialismo histórico de Marx e da Psicologia Histórico-Cultural de Vygotsky.

Saviani (2008) afirma a contribuição de Marx à pedagogia histórico-crítica (PHC), haja vista que nos fundamentos teóricos desta está a dialética, em especial a dialética do movimento real, histórica. É esta a concepção que compreende e explica as formas como são produzidas as relações sociais, bem como a educação no referido processo.

A partir da concepção teórica de Vygotsky, destacamos sua contribuição ao incluir, no processo ensino-aprendizagem, quem aprende, e quem ensina, bem como a relação entre os dois.

[...] para compreender adequadamente o desenvolvimento devemos considerar não apenas o nível de desenvolvimento real da criança, mas também seu nível de desenvolvimento potencial, isto é, sua capacidade de desempenhar tarefas com a ajuda de adultos ou de companheiros mais capazes (VYGOTSKY apud OLIVEIRA, 1997, p. 59).

Filosofia e Educação - ISSN 1984-9605 - v. 4, no 1, abril-setembro de 2012 
Esta pedagogia surgiu como proposta de superação tanto das pedagogias não-críticas ou liberais - que se materializam nas tendências ou escolas tradicional, nova e tecnicista - como das teorias crítico-reprodutivistas: teoria da escola enquanto aparelho ideológico de estado, teoria da escola dualista e teoria do sistema enquanto violência simbólica.

As teorias crítico-reprodutivistas, por sua vez, compreendem a educação como um instrumento de discriminação social, sendo assim um fator de marginalização. Para Saviani, tais teorias não se formam por meio de uma proposta pedagógica. No entanto, identificam o fracasso no qual a escola reproduz as relações sociais de produção, reproduzindo a alienação dos alunos.

[...] trata-se de retomar vigorosamente a luta contra a seletividade, a discriminação e o rebaixamento de ensino das camadas populares. Lutar contra a marginalidade através da escola significa engajar-se no esforço para garantir aos trabalhadores um ensino de melhor qualidade possível nas condições históricas atuais. O papel de uma teoria crítica da educação é dar substância concreta a essa bandeira de luta de modo a evitar que ela seja apropriada e articulada com os interesses dominantes (SAVIANI, 2009, p. 29).

Assim, como superação das citadas teorias, a pedagogia histórico-crítica tem, em seu bojo, uma perspectiva de educação que atenda aos interesses da maioria marginalizada ao longo do contexto histórico brasileiro. Na PHC, o ato educativo constitui-se como

[...] ato de produzir, direta e intencionalmente, em cada indivíduo singular, a humanidade que é produzida histórica e coletivamente pelo conjunto dos homens. Assim, o objeto da educação diz respeito, de um lado, à identificação dos elementos culturais que precisam ser assimilados pelos indivíduos da espécie humana para que eles se tornem humanos e, de outro lado e concomitantemente, à descoberta das formas mais adequadas para atingir esse objetivo (SAVIANI, 2008, p.13).

Filosofia e Educação - ISSN 1984-9605 - v. 4, no 1, abril-setembro de 2012 
Este ato, na prática, muitas vezes não ocorre da forma apresentada. Isto, considerando que nem sempre existe uma consciência, por parte dos professores, sobre esta concepção.

\section{A pedagogia histórico-crítica como política pública no Paraná}

A pedagogia histórico-crítica - cujas raízes históricas têm como marco inicial o ano de 1979 - é tributária da concepção dialética, especificamente na versão do materialismo histórico, sustentada em suas bases psicológicas, pela psicologia histórico-cultural de Vygotsky. Nessa visão, a educação é entendida como mediação no seio da prática social global.

Tal pedagogia tem uma concepção inserida na pedagogia socialista de inspiração marxista. Sendo assim, pressupõe a crítica radical à sociedade atual e a luta pela sua transformação. Segundo Saviani, a "exigência do trabalho pedagógico decorre da natureza histórica do ser humano: A natureza humana não é dada ao homem mas é por ele produzida sobre a base da natureza biofísica" (2008, p.13).

Neste contexto, a década de 1980 foi cenário de um intenso processo de afirmação dos direitos e deveres dos cidadãos, luta contra a ditadura militar e conquista de liberdade política e organizacional. Foi a década da redemocratização, das eleições livres nos estados e capitais, a causa da anistia, de afirmações de classes e categorias emancipatórias. A educação e o resgate da escola pública estiveram no centro destas lutas.

Nas eleições de 1982, o Estado do Paraná elegeu o governador José Richa, do Movimento Democrático Brasileiro (MDB), o que representou o início de uma educação envolvendo a categoria nas decisões das políticas educacionais.

Durante o mandato de Richa (1982-1986), a categoria de professores do Paraná realizou estudos e debates em torno de uma proposta de educação democrática. Nesse processo de transição, os educadores mobilizaram- se para a universalização da educação pública e de qualidade social para todos, construiu-se uma nova proposta de educação, fundamentada na concepção da pedaFilosofia e Educação - ISSN 1984-9605 - v. 4, no 1, abril-setembro de 2012 
gogia histórico-crítica. No primeiro ano deste governo, a SEED elaborou um documento norteador das políticas educacionais, intitulado de "Políticas SEEDPR. Fundamentos e Explicitação/1983". Os principais objetivos desse documento foram: o desenvolvimento do compromisso político dos educadores com a maioria da população, a abertura para a participação popular e a apresentação de uma concepção de escola aberta e democrática, empenhada em ofertar o conhecimento como patrimônio coletivo da sociedade, priorizando o ensino do então primeiro grau.

O governo Richa, como todo governo oposicionista, estabeleceu a chamada política de impacto, que se traduziu em diversas ações: nas eleições diretas para diretor de escola; não obrigatoriedade do uniforme escolar; realização da Semana Pedagógica em substituição ao dia de planejamento; descentralização administrativa da SEED mediante a ampliação de oito para vinte e dois Núcleos Regionais de Educação (NRE); busca de parcerias com os municípios para a ampliação e construção de novas unidades escolares. Além disso, o acervo bibliográfico foi ampliado para a consolidação do trabalho de alfabetização por meio de distribuição de livros didáticos. Foram criados, também, vinte e dois Centros de Línguas Estrangeiras Modernas (CELEM) e, à educação especial foi destinado um tratamento específico, incluindo a formação e capacitação dos docentes para trabalhar com crianças com necessidades especiais, expandindo programas às escolas regulares, além de assistências e avaliação psicoeducacional, com distribuição de equipamentos e realização de convênios com o objetivo de alcançar mais recursos e equipamentos. Para a categoria do magistério foram ofertados cursos de capacitação e a realização de concursos públicos, além de outros benefícios, como reajustes salariais.

Em relação à melhoria da qualidade do ensino, pouco se pôde constatar. A despeito dos avanços conquistados em relação ao período do regime militar, as ações educacionais do governo do Paraná, indicam que a apropriação da pedagogia histórico-crítica como fundamento teórico balizador das políticas educacionais, com o objetivo de redemocratizar a escola, constituiu-se num discur-

Filosofia e Educação - ISSN 1984-9605 - v. 4, no 1, abril-setembro de 2012 
so ideológico, simbolizando a transição de uma sociedade autoritária para uma sociedade democrática, ainda que no âmbito dos limites do liberalismo.

Em 1987, ainda pela legenda do PMDB, Álvaro Dias, assumiu o governo do Paraná. Em relação à educação e ao ensino, o novo governo priorizou o projeto pedagógico, por acreditar que a proposta de uma escola democrática possa ser construída a partir da crítica da escola pública atual. Para tanto, propôs a reordenação do sistema visando a produtividade, já que os índices apresentados não eram satisfatórios. Segundo dados do documento "Reflexões sobre Alfabetização: subsídios da Secretaria de Estado da Educação" (1987), do Estado do Paraná, o índice de reprovação era muito significativo. Depois de um ano de escolaridade, de cada cem crianças que ingressavam na escola pública do Paraná, em torno de 46,4\% eram desestimuladas a continuar o processo de alfabetização (por evasão ou reprovação) que resulta da aplicabilidade de critérios pouco realistas.

Neste contexto, o governo propôs a reorganização da escola pública do $1^{\circ}$ grau, criando o Ciclo Básico de Alfabetização (CBA), com o objetivo de reverter o fracasso escolar. Portanto, foram elaborados documentos: o "Currículo Básico para a Escola Pública do Estado do Paraná" e as "Propostas para a Reestruturação do $2^{\circ}$ grau", como também os chamados Cadernos do $2^{\circ}$ grau, que se constituíram numa forma estruturada de didatização da pedagogia históricocrítica. O Currículo Básico possibilitou aos professores o acesso aos fundamentos teórico-filosóficos da referida pedagogia, nas diversas disciplinas, auxiliando-os na organização da sequência e ordenação dos conteúdos, de acordo com a disciplina e a série.

É importante ressaltar que a pedagogia histórico-crítica emergiu também nesse momento histórico, com a preocupação de atuar de modo crítico no campo pedagógico, separando a pedagogia oficial da ditadura militar - o tecnicismo e o chamado ceticismo na tendência crítico-reprodutivista, que se propunha a fazer a crítica da escola enquanto reprodutora, isto é, inculcadora das relações sociais e culturais do modo de produção capitalista.

Filosofia e Educação - ISSN 1984-9605 - v. 4, no 1, abril-setembro de 2012 
Desta forma, o processo contínuo de elaboração dessa pedagogia perpassa os documentos norteadores da política educacional paranaense, na qual "A escola aberta e democrática deverá empenhar-se na oferta do conhecimento como patrimônio coletivo da sociedade, e de forma participativa, conquistar soluções duradouras para os problemas do povo" (PARANÁ, 1984, p.01).

Isto significa que a proposta desta gestão fundamenta sua mensagem política da educação ao aliar a democratização à competência da escola. Sendo assim, trata-se de um projeto que concebe a educação voltada à preparação e formação de indivíduos por meio da transmissão e produção de conteúdos significativos, garantindo o aprofundamento e o domínio dos princípios científicos, tecnológicos, filosóficos e artísticos, socialmente elaborados.

Apesar do discurso democrático, a gestão Álvaro Dias caracterizou-se por momentos difíceis de lutas, atos arbitrários e violentos por parte do governo, os quais consolidaram- se em duas grandes greves, ocorridas em 1988 e 1990, com reivindicações que não foram atendidas pelo governo do estado. Isso demonstra a grande contradição existente entre os objetivos anunciados com a implantação do Ciclo Básico e a atuação do governo do Paraná. De um lado anunciava-se a oferta de uma educação científica e de qualidade aos educandos, ligada a qualificação profissional dos educadores e sua consequente valorização e, de outro, a prática de desvalorização da categoria do magistério, desde a defasagem salarial, ações autoritárias e violentas para atenuar as reivindicações até atitudes desmedidas e antidemocráticas exatamente num momento em que a escola estava sendo anunciada com espaço democrático.

Diante disso, considera-se que vários fatores contribuíram para a não efetivação dessa proposta. Um deles foi a oficialização da pedagogia históricocrítica por parte do Estado, distorcendo seus objetivos e escamoteando suas bases filosóficas de cunho socialista, a partir de uma interpretação de cunho liberal e capitalista, resultando na má interpretação desta pedagogia por parte dos professores.

Em tal contexto de insatisfação e insegurança quanto às propostas governamentais, passou-se para o governo Roberto Requião, iniciado em 1991,

Filosofia e Educação - ISSN 1984-9605 - v. 4, no 1, abril-setembro de 2012 
completando o terceiro mandato consecutivo do PMDB. No aspecto educacional, esse governo pretendia ser uma nova era para a escola pública paranaense, com propostas modernas, de qualidade de ensino, gestão democrática, eficiência e participação comunitária. Tentando mostrar o novo, o governo ocultou que as propostas aproximavam-se da gestão anterior.

O programa educacional intitulado "Uma Educação para a Modernidade”, uma proposta de ações governamentais para o ensino do Paraná (PMDB 1990), elegeu a educação como meta prioritária de governo. Entretanto, nenhuma estimativa da situação educacional fora realizada e, nem mesmo uma análise das gestões anteriores. Assim, novas ações foram efetivadas, medidas implantadas, sem a preocupação na continuidade, ao menos, considerando o que estava dando certo e fazendo revisão das falhas.

Para garantir a reorganização e a qualidade da escola pública, a mesma foi orientada para a autonomia na medida em que foi incentivada à elaboração e execução do Projeto Político Pedagógico, também se fortaleceu o processo de municipalização do ensino fundamental de $1^{\mathrm{a}}$ à $4^{\mathrm{a}}$ série (iniciada na gestão anterior com o Protocolo de Intenções entre Estado/Município), que procurava partilhar serviços e encargos para a universalização do ensino, foram constituídos os Conselhos Escolares, foi elaborado o Regimento Escolar Único, implementação do Currículo Básico, autonomia e gestão democrática das escolas, elaboração do Plano de Capacitação Docente, vinculado ao projeto de Construção da Escola Cidadã no Paraná, a eleição de diretores foi substituída pela consulta à comunidade, eliminação da reprovação de $1^{\mathrm{a}}$ à $4^{\mathrm{a}}$ série, com a extensão do Ciclo Básico para quatro anos (Decreto $n^{\circ} 2.325$, de 25 de maio de 1993). Nesse período iniciaram-se também as negociações entre o governo do Paraná e as Instituições de Financiamento: Banco Internacional para a Reconstrução e Desenvolvimento (BIRD) e o Banco Mundial (BID).

Apesar da forma de implantação das propostas apresentadas nessa gestão, esse governo foi conflituoso com os trabalhadores da educação que, ora passou por medidas democratizantes, ora revelou-se autoritário e centralizador. No entanto, em abril de 1994, o então governador licenciou-se, assumindo o vice Ma-

Filosofia e Educação - ISSN 1984-9605 - v. 4, no 1, abril-setembro de 2012 
rio Pereira, que no campo educacional não efetivou grandes mudanças. Em 1995, ganhou as eleições, Jaime Lerner, permanecendo no governo durante duas gestões. Neste período a educação passou por momentos muito difíceis, considerando que, de certa forma, caracterizava-se de cunho liberal. O Paraná foi piloto na implantação das propostas do governo federal (Fernando Henrique Cardoso) com políticas de minimização do estado.

Em 2003 Roberto Requião assumiu, novamente, o governo do Paraná e, mais uma vez a pedagogia histórico-crítica apareceu como um discurso revolucionário de educação. Assim como no primeiro governo Requião, essa pedagogia foi disseminada politicamente e, neste mandato, percebemos que, novamente, existiu a intenção de permanência da mesma com o envolvimento da categoria educacional.

Em breve análise das propostas educacionais do atual governo, podemos perceber que houve grandes avanços e melhorias com relação às políticas públicas para a educação. Já no primeiro ano de mandato (2003), a Secretaria de Estado da Educação (SEED) iniciou o processo de reformulação das Diretrizes Curriculares para a Educação Básica. Processo este marcado pela participação ativa dos profissionais da educação, mediante cursos de capacitação fundamentados por referenciais teóricos que proporcionaram uma reflexão sobre a prática educativa, superando o modelo utilizado na gestão anterior, com foco em programas motivacionais.

No processo introdutório de reformulação, a SEED elaborou um documento que serviu de base inicial aos estudos realizados, no qual apresentava os passos a serem seguidos para a elaboração das diretrizes.

Segundo Arco-Verde (2003) tal processo deveria contemplar

[...] a visão de mundo, de homem e de escola; a concepção de Educação, suas teorias e práticas; a contextualização da Educação frente a conjuntura nacional, os estudos da realidade sócio-econômica e cultural da região; o perfil do aluno e do professor paranaense, bem como da escola e dos órgãos colegiados; as diretrizes curriculares nacionais; a legislação educacio-

Filosofia e Educação - ISSN 1984-9605 - v. 4, no 1, abril-setembro de 2012 
nal atualizada, os resultados de estudos e demandas escolares; as bases do Projeto Pedagógico da Escola (PARANÁ, 2003, p.14).

Vale destacar que, ao definir os passos para a elaboração das diretrizes, a SEED apresentou a necessidade de definir uma concepção de mundo, de homem, de escola e de educação, e estas concepções estão fundamentadas no materialismo histórico. Define ainda, a função da educação escolar como aquela que propicia o acesso ao conhecimento científico de forma unitária, independente da classe social do aluno. Quando faz referência ao processo metodológico de ensino, são apresentados os cinco passos elaborados por Saviani na sistematização da pedagogia histórico-crítica.

Apesar da referência aos cinco passos, a denominação não é referenciada no texto em pauta, assim como não aparece nos demais documentos oficiais. A pedagogia histórico-crítica, presente nos inúmeros discursos e documentos da SEED, desde os anos de 1983, ainda não foi apropriada na sua totalidade pelos profissionais da educação.

Sabemos que os avanços do governo, gestão 2003-2010, são inúmeros em relação à educação, resgatando seu caráter público. Grande número de conquistas foram obtidas, como realização de concurso público para professores e pedagogos, política de formação continuada, plano de carreira dos professores, eleição para diretores de escolas, elaboração das Diretrizes Curriculares Estaduais, entre outros. No entanto, ainda temos muito a conquistar mesmo percebendo o movimento dialético na área educacional. Para a gestão 2011/2014 Richa volta para o governo estadual. Não o José, mas seu filho Carlos Alberto, de outra trajetória política, Partido Social Democrático Brasileiro (PSDB). Portanto, com vistas a outro projeto educacional para o estado do Paraná.

Considerando que ainda é cedo para uma análise mais profunda sobre o encaminhamento da educação, o que pode ser dito é que, até o presente momento, o governo, em especial, o Secretário da Educação, tem mantido uma relação estreita com a Associação dos Profissionais da Educação (APP Sindicato), gerindo junto ao governador ações de avanço para a categoria.

Filosofia e Educação - ISSN 1984-9605 - v. 4, no 1, abril-setembro de 2012 


\section{A pedagogia histórico-crítica na formação do professor}

O conhecimento das diferentes teorias da educação é essencial aos educadores auxiliando-os no entendimento de sua prática e situando-o no universo pedagógico, visto que na pedagogia tradicional o papel da escola é transmitir os conhecimentos acumulados pela humanidade, os trabalhos nesta escola se organizam com a centralização do papel do professor, o qual transmite os conhecimentos aos alunos e a estes é importante assimilá-los, utilizando-se principalmente da memorização.

Na pedagogia nova o importante não era aprender, mas aprender a aprender. A escola deveria agrupar os alunos segundo áreas de interesses, em um lugar diferenciado com materiais didáticos, bibliotecas modernas e atualizadas. $\mathrm{O}$ professor seria um orientador da aprendizagem estimulando os alunos, em que a iniciativa dos conteúdos a serem estudados caberia aos próprios educandos, assim as aulas deveriam ser diferenciadas, divertidas, coloridas, movimentadas e principalmente inusitadas. Saviani (2008) descreve a organização escolar na Escola Nova e coloca que

Essa teoria preconiza que as crianças aprendem em atividade, interagindo com outras crianças sob orientação e supervisão do professor, respondendo aos estímulos e desafios do ambiente. Assim, a sala de aula é barulhenta em decorrência da multiplicação dos estímulos internos e externos (2008, p. 118).

Apesar do entusiasmo inicial, a Escola Nova organizou-se na forma de escolas experimentais, muito equipadas e com acesso a pequenos grupos da elite. Esse tipo de escola não conseguiu alterar os sistemas escolares, pois além de outras razões o custo era muito alto em relação à escola tradicional. Na metade do século XX, o escolanovismo não apresentou os resultados esperados, havendo assim grande frustração entre os meios educacionais, "É melhor uma boa escola para poucos do que uma escola deficiente para muitos" (SAVIANI, 2009, p.10).

Filosofia e Educação - ISSN 1984-9605 - v. 4, no 1, abril-setembro de 2012 
Na pedagogia tecnicista o elemento principal deve ser a organização dos meios, sendo que o professor e o aluno ocupavam um segundo plano, e os executores de um processo cujo planejamento, coordenação eram destinados aos especialistas com habilitação, neutros e imparciais, é o processo que define o que professores e alunos devem fazer e como e quando farão. Assim sendo a pedagogia tecnicista aumentou os problemas no campo educacional, havendo uma descontinuidade e tornando o trabalho pedagógico insustentável, havendo altos índices de evasão e repetência nas escolas.

A pedagogia histórico-crítica surgiu, no início dos anos 1980, como resposta a necessidade amplamente sentida entre os educadores brasileiros de superação dos limites tanto das pedagogias não criticas, representadas pelas concepções tradicional, como das visões crítico-reprodutivistas, expressas na teoria da escola como aparelho ideológico do Estado, na teoria da reprodução e na teoria da escola dualista. Já na década de 1990, com um governo dito neoliberal ficou caracterizado as reformas educativas pelo neoconservadorismo, surgindo com isso os movimentos progressistas com sua adesão à pedagogia históricocrítica.

Com a pedagogia histórico-crítica surgiu o entendimento da necessidade da formação continuada do professor. Na visão de que o fazer pedagógico, que ultrapassa a sala de aula e a determina, configura-se como essencial na busca de novas formas de organizar a escola para que esta seja efetivamente democrática.

Temos que avançar e sair do corporativismo dos especialistas para a necessidade política do pedagogo, no processo de democratização da escolaridade.

Qual a verdadeira função do curso de Pedagogia? Formar professores, especialistas ou ambos? As mudanças foram poucas de acordo com a Resolução $n^{\circ}$ 252/69 e nenhuma como algo realmente inovador. Alterações pouco significativas, pois na maior parte dos casos foi mantida a prática da grade curricular e os mesmos conteúdos das antigas disciplinas. Nos cursos de licenciatura tam-

Filosofia e Educação - ISSN 1984-9605 - v. 4, no 1, abril-setembro de 2012 
bém não houve grandes mudanças desde a Resolução $n^{\circ}$ 292/62, apenas tentaram-se diferentes formas de organização do percurso da formação.

Compete ao educador buscar o conhecimento nas diversas áreas econômicas e sociais que marcam cada época, para compreender a complexidade e diferentes concepções das práticas pedagógicas, transformando este conhecimento em saber escolar, que expressem o desejo coletivo da sociedade.

Hoje, com o novo projeto econômico e social para o país, é possível trabalhar a transversalidade nas políticas públicas, buscando com isso a compreensão de que o educador não é apenas um distribuidor dos conhecimentos socialmente produzidos, mas formador de opinião, determinadas pelas relações sociais e produtivas de mediação entre o aluno e o conhecimento, onde o coletivo permita a cada um desenvolver-se como indivíduo e como humanidade.

A formação do professor exige hoje novas atitudes e comportamentos perante a sociedade e o trabalho, uma nova ética. Na luta contra o neoliberalismo, é preciso responsabilidade crítica, voltada para a preservação da vida para a construção de uma sociedade mais justa e igualitária, superando a exclusão em face da já histórica situação de desigualdade em nosso país. Segundo Kuenzer

É preciso reiterar a urgência da crítica aos atuais procedimentos de formação do professor e, em decorrência, do papel das faculdades de educação, em busca de sua superação, porquanto esta etapa de desenvolvimento das forças produtivas também exige um educador de novo tipo, que esteja capacitado para compreender a nova realidade, apoiando-se nas distintas áreas do conhecimento para produzir ciência pedagógica. Que permita orientar as novas práticas educativas, sempre dinâmicas, que privilegiem os conteúdos necessários, as adequadas formas metodológicas, os atores, os espaços, as formas de acompanhamento e crítica, na perspectiva dos fins da educação, com utopia construída pela vontade coletiva (1998, p. 04-05).

A partir dessas considerações podemos assegurar que é preciso começar um processo de construção coletiva que expresse a vontade dos diversos atores Filosofia e Educação - ISSN 1984-9605 - v. 4, no 1, abril-setembro de 2012 
sociais, transformar as faculdades de educação em centros dinâmicos de produção do conhecimento, buscando a criação de modelos curriculares mais adequados e que privilegiem a totalidade na formação de profissionais de educação para os diferentes níveis, modalidades e áreas de ensino. É preciso rever as atuais formas de organização para enfrentar as críticas colocadas pelo neoliberalismo, que não servem para atender as novas demandas da sociedade que queremos, pois são tradicionais e pouco competentes.

Para formarmos esse novo educador é preciso rever a história, fazer autocrítica e buscar novas formas de organização, para enfrentar o capitalismo enraizado em nossa história sem que os verdadeiros interessados e seus representantes tivessem o direito a participar das decisões sobre seu destino, marcados pela exclusão e pela aceitação de que a cidadania não é para todos.

Para Mészáros

O tempo histórico dos indivíduos não precisa conflitar sempre com as determinações objetivas do tempo histórico da humanidade. É também passível de colocar- se em harmonia com o tempo da humanidade. Hoje isso pode ser alcançado se os indivíduos sociais adotarem conscientemente as alternativas positivas que apontam na direção do futuro sustentável da humanidade. A especificidade e a urgência de nosso tempo histórico determinam que eles não apenas podem, mas devem fazê-lo (2007, p.39-40).

Compreender a escolha dos profissionais da educação do Estado do Paraná pela institucionalização da pedagogia histórico-crítica como norteadora do currículo, e em consequência das ações da escola, compreende a reflexão para a necessidade dos educadores de que os conhecimentos socialmente construídos ao longo de séculos de história, possam ser assimilados e sirvam como parâmetro para a instituição de melhorias nos meios sociais, em busca da formação da consciência crítica coletiva e melhor atuação na sociedade vigente, procurando questionar e alterar as práticas impostas pelo capitalismo.

Filosofia e Educação - ISSN 1984-9605 - v. 4, no 1, abril-setembro de 2012 
Neste sentido, a pedagogia histórico-crítica vem ao encontro das necessidades dos educadores paranaenses, pois visa à reflexão e superação de questões que devem permear as ações dos docentes, conforme descreve Saviani

É nesse contexto que emerge a pedagogia histórico-crítica como uma teoria que procura compreender os limites da educação vigente e, ao mesmo tempo, superá-los por meio da formulação de princípios, métodos e procedimentos práticos ligados à organização do sistema de ensino quanto ao desenvolvimento dos processos pedagógicos que põem em movimento a relação professor-alunos no interior das escolas (2008, p. 119).

Uma outra questão, abordada pelo autor e também se faz importante colocar, visto que em termos de futuro, pode-se constituir em um problema, está situado na questão do Desafio da Descontinuidade, ou seja, a importância do tempo necessário para que as ações e propostas estudadas e implementadas se concretizem

Parece que as nossas iniciativas em educação pecam por uma extrema descontinuidade, e isso, a meu ver, entra em contradição com uma das características próprias da atividade educacional, com uma das características que se insere na natureza e especificidade da educação, que é a exigência de um trabalho que tenha continuidade, que dure um tempo suficiente para provocar um resultado irreversível. Sem se atingir o ponto de irreversibilidade, os objetivos da educação não são alcançados (idem, 2008, p.109).

Trata-se, portanto, da preocupação dos educadores de que a pedagogia histórico-crítica, em termos de futuro, derivada de outras políticas públicas com diferentes interesses voltados à educação, seja substituída, em nome das chamadas "inovações pedagógicas", tão presentes na história da educação no Brasil. Porém, tal previsão não ocorrerá com o fortalecimento dos estudos de fundamentação teórica e das concepções teóricas que embasam a pedagogia históri-

Filosofia e Educação - ISSN 1984-9605 - v. 4, no 1, abril-setembro de 2012 
co-crítica. Dessa forma, a referida pedagogia ficará arraigada na formação e ações práticas dos professores do Estado do Paraná.

\section{Considerações finais}

A proposição da obra de Saviani está diretamente ligada ao nome de seu livro: História das Ideias Pedagógicas no Brasil (2007). Assim, considerando o desafio do tempo histórico, proposto por Mészáros, Saviani apresenta uma periodização diferente das até então feitas por outros autores como Romanelli (1978) e Ribeiro (1998), entre outros, sob o viés econômico.

O presente relato, portanto, além de apresentar o projeto desenvolvido ao longo de dois anos no Colégio Estadual "Cristo Rei”, apresenta também o quarto período explicitado na obra de Saviani, As idéias pedagógicas no Brasil - entre 1969 e 2001 -, mais especificamente a década de 1980. Porém, ampliao até os dias de hoje, evidenciando a emergência da pedagogia histórico-crítica.

Desta forma, o desafio em relação ao referido projeto foi a elaboração de um artigo científico estabelecendo a ligação entre a prática cotidiana escolar e o que foi estudado. Foram as vivências dos envolvidos, bem como a reflexão da obra que possibilitaram o resgate do tempo educacional histórico no estado do Paraná considerando o entendimento a falta dele no que tange à Pedagogia Histórico- Crítica como base e referência da práxis pedagógica.

O desafio estabelecido, de retratar essa trajetória, trazendo à tona as dificuldades, os avanços, e também, muitas vezes, a estagnação na educação faz com que, dentro das possibilidades existentes, como afirma Mészaros (2007) é pela necessidade que tanto a consciência individual quanto a consciência social devem ter como ponto de encontro o interesse do avanço humano positivo.

Destarte, mesmo com o fim do projeto e hoje, com o grupo de pesquisa, professores e acadêmicos reúnem-se para o estudo da PHC, vislumbrando a possibilidade de exercer a prática por meio desta teoria. Desafio posto para a compreensão, cada vez maior, do papel da educação escolar e da instituição escola na sociedade capitalista vigente.

Filosofia e Educação - ISSN 1984-9605 - v. 4, no 1, abril-setembro de 2012 


\section{Referências}

KUENZER, A. Z. A formação de educadores no contexto das mudanças no mundo do trabalho: Novos desafios para as faculdades de educação. In: Revista Educação \& Sociedade. v.19. n.63. Campinas, 1998. Disponível em: $<\underline{\text { http://www.scie- }}$ lo.br/scielo.php?pid $=$ S0101-

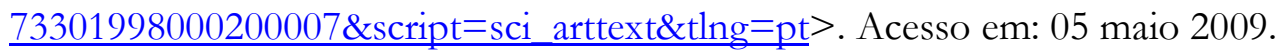
MÉSZAROS,I. O desafio e o fardo do tempo histórico: o socialismo no século XXI. Trad. Ana Cotrim, Vera Cotrim. São Paulo: Boitempo, 2007.

OLIVEIRA, M.K. VYGOTSKY: Aprendizagem e desenvolvimento: um processo sócio-histórico. São Paulo: Scipione, 1997.

PARANÁ. Secretaria de Estado da Educação. Políticas SEED-PR: fundamentos e explicitação. 3. ed. Curitiba: SEED, 1984.

. SEED. Projeto Pedagógico: 1987-1990. Curitiba: SEED, 1987.

. SEED. Currículo Básico para a Escola Pública do Estado do Paraná. Curitiba, PR: SEED, 1990.

. SEED/SUED. Paraná: Construindo a escola cidadã. Curitiba, PR:

SEED, 1992.

. SEED/SUED. Introdução às Diretrizes Curriculares. Texto elaborado pela Prof. ${ }^{a}$ Dr. ${ }^{a}$ Yvelise Freitas de Souza Arco-Verde (Superintendente da Educação da SEED/PR) para as discussões nas escolas da rede pública estadual de ensino do Paraná. Curitiba, 2003.

PMDB. Diretrizes de Governo: Politica de Educação. (José Richa). Curitiba, 1982. . Diretrizes de Governo para debates - Governo Álvaro Dias. Curitiba, 1986. . Uma educaşão para a modernidade - propostas de ações governamentais para o ensino do Paraná. (Roberto Requião). Curitiba, 1990.

SAVIANI, D. Escola e Democracia. 41 ed. Campinas: Autores Associados, 2009. . Pedagogia histórico-crítica: primeiras aproximações. 10. ed. rev. Campinas: Autores Associados, 2008. . História das Idéias Pedagógicas no Brasil. Campinas: Autores Associados, 2007.

Filosofia e Educação - ISSN 1984-9605 - v. 4, no 1, abril-setembro de 2012 